\title{
RANCANGAN STRIP PLOT MODEL TETAP
}

\author{
Triastuti Wuryandari ${ }^{1}$, Yuciana Wilandari ${ }^{1}$, Noor Afifah ${ }^{2}$ \\ ${ }^{1}$ Staf Jurusan Matematika FMIPA UNDIP \\ ${ }^{2}$ Alumni Jurusan Matematika FMIPA UNDIP
}

\begin{abstract}
The experiment involve the study of the effects of two or more factors can be used the factorial designs. The factorial designs have several advantages. They are more efficient than one factor at a time experints. Furthermore, a factorial designs is necessary when interaction may be present to avoid misleading conclutions. In the Strip Plot design is factorial two factors which random factors aren't based on main plot or the whole plot but the important is it's interaction. There are three error in the Strip plot. They are error caused by factor A, error caused by factor B and error by $\mathrm{A}$ and $\mathrm{B}$ interaction.
\end{abstract}

Keywords: Factorial, Strip Plot, Interaction

\section{Pendahuluan}

Percobaan faktorial baik dalam Rancangan Acak Lengkap (RAL), Rancangan Acak Kelompok (RAK) maupun Rancangan Bujur Sangkar Latin (RBSL) ditujukan untuk meneliti pengaruh utama dan interaksi dengan derajat ketelitian yang sama. Kadang-kadang suatu percobaan dua faktor diinginkan ketepatan untuk mengukur interaksi antar dua faktor diharapkan lebih tinggi daripada mengukur pengaruh utama faktor manapun dari dua faktor yang digunakan [4]. Dalam situasi seperti ini rancangan yang sesuai digunakan adalah rancangan strip plot.

Rancangan Strip Plot mirip dengan rancangan split plot. Pada Split Plot satu faktor diletakkan pada petak utama dan faktor lainnya diletakkan pada anak petak tetapi pada Strip Plot kedua faktor merupakan petak utama [1]. Model yang digunakan adalah model tetap, random dan campuran. Dalam tulisan ini hanya akan dibahas untuk Strip Plot model tetap. Pembahasan ini meliputi model linear, asumsi dan cara pembuktiannya, hipotesis yang dapat diambil, tabel Anova dan uji lanjutnya. Untuk memperjelas pembahasannya diberikan contoh penerapan dan penyelesaian dengan paket program SAS 6.12 dan MINITAB 14.12

\section{Deskripsi Teoritis}

Rancangan Strip Plot merupakan rancangan faktorial dengan pemeriksaan yang lebih teliti diutamakan pada interaksinya dibanding faktor utamanya. Dalam Strip Plot tidak ada pembagian petak utama dan anak petak, masing-masing bagian sama dengan petak utama itu sendiri. Ini berimplikasi ada kesetangkupan tertentu antara kedua faktor tersebut sehingga yang satu mempunyai kemungkinan yang sama untuk disebut sebagai perlakuan petak utama [1]. Misalnya suatu penelitian menggunakan faktorial dua faktor dan diutamakan ketelitian pada interaksinya dibanding faktor utamanya. Faktor A dengan a taraf dan faktor $\mathrm{B}$ dengan $\mathrm{b}$ taraf dan unit percobaannya dikelompokkan menjadi n kelompok, maka model linearnya adalah

$$
\begin{aligned}
& Y_{i j k}=\mu+K_{k}+\alpha_{i}+\delta_{i k}+\beta_{j}+\rho_{j k}+(\alpha \beta)_{i j}+\varepsilon_{i j k} \\
& \mathrm{i}=1,2, \ldots, \mathrm{a} ; \quad \mathrm{j}=1,2, \ldots, \mathrm{b} ; \quad \mathrm{k}=1,2, \ldots, \mathrm{n}
\end{aligned}
$$

dengan: 
$Y_{i j k} \quad$ : pengamatan pada kel ke-k, faktor A taraf ke-i, faktor B taraf ke-j

$\mu \quad$ : rata-rata keseluruhan

$K_{k} \quad$ : pengaruh kelompok ke k

$\alpha_{i} \quad$ : pengaruh faktor A taraf ke-i

$\delta_{i k} \quad:$ komponen galat oleh faktor A taraf ke-i dan kel ke-k (galat a)

$\beta_{j} \quad$ : pengaruh faktor B taraf ke-j

$\rho_{j k} \quad:$ komponen galat oleh faktor B taraf ke-j dan kel ke-k (galat b)

$(\alpha \beta)_{i j}$ : pengaruh interaksi faktor A taraf ke-i dan faktor B taraf ke-j

$Y_{i j k} \quad$ : komponen galat oleh faktor A taraf ke-i, faktor B taraf ke-j dan kel ke-k

Asumsi yang harus dipenuhi dalam model tetap adalah:

$$
\begin{aligned}
& \sum_{i=1}^{a} \alpha_{i}=0 ; \sum_{j=1}^{b} \beta_{j}=0 ; \sum_{k=1}^{n} K_{k i}=0 \\
& \sum_{i=1}^{a}(\alpha \beta)_{i j}=\sum_{j=1}^{b}(\alpha \beta)_{i j}=\sum_{i=1, j=0}^{a, b}(\alpha \beta)_{i j}=0 \\
& \delta_{i k} \sim N\left(0, \sigma_{\delta}{ }^{2}\right) \quad \rho_{j k} \sim N\left(0, \sigma_{\rho}{ }^{2}\right) \quad \varepsilon_{i j k} \sim N\left(0, \sigma^{2}\right)
\end{aligned}
$$

Untuk estimasi parameternya digunakan metode kuadrat terkecil. Untuk pengujian asumsi normalitas digunakan uji Kolmogorov Smirnof dan uji homogenitas variansi digunakan uji Bartlett.

Pengacakan perlakuannya untuk Rancangan Strip Plot adalah sebagai berikut:

- $\quad$ Pilihlah kelompok unit percobaan secara acak

- $\quad$ Tempatkan taraf-taraf faktor A secara acak pada setiap kelompok mengikuti pola lajur

- $\quad$ Tempatkan taraf-taraf faktor B secara acak pada setiap kelompok mengikuti pola baris. [1]

Misalnya suatu percobaan untuk mengetahui pengaruh 2 faktor yaitu Jenis pupuk ( P0, P1, P2) dan Penyinaran $(\mathrm{E} 0, \mathrm{E} 1)$ terhadap produksi rumput untuk pakan ternak dan diulang 3 kali. Maka pengacakannya sebagai berikut:
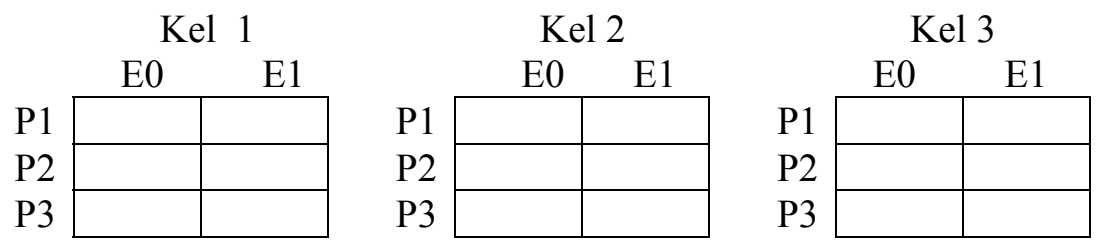

Hipotesis yang bisa diambil adalah sebagai berikut:

1. $H_{0}: \alpha_{1}=\alpha_{2}=\ldots=\alpha_{a}=0$ (tidak ada pengaruh faktor A terhadap respon)

$H_{1}$ : paling sedikit ada satu dengan $\alpha_{i} \neq 0$ (ada pengaruh faktor A terhadap respon)

2. $H_{0}: \beta_{1}=\beta_{2}=\ldots .=\beta_{b}=0$ (tidak ada pengaruh faktor B terhadap respon)

$H_{1}$ : paling sedikit ada satu dengan $\beta_{j} \neq 0$ (ada pengaruh faktor B terhadap respon) 
3. $H_{0}:(\alpha \beta)_{11}=(\alpha \beta)_{12}=\ldots .=(\alpha \beta)_{a b}=0$ (tidak ada pengaruh interaksi faktor $\mathrm{A}$ dan faktor B terhadap respon)

$H_{1}$ : paling sedikit ada sepasang $(\mathrm{i}, \mathrm{j})$ dengan $(\alpha \beta)_{i j} \neq 0$ (ada pengaruh faktor $\mathrm{A}$ dan faktor B terhadap respon)

Tabel 1: Lay Out data untuk Rancangan Strip Plot

\begin{tabular}{|c|c|c|c|c|c|c|}
\hline Faktor A & Faktor B & \multicolumn{4}{|c|}{ Kelompok } & Total \\
\hline & & 1 & 2 & $\ldots$ & $\mathrm{N}$ & $Y_{i j}$ \\
\hline \multirow[t]{4}{*}{1} & 1 & $Y_{111}$ & $Y_{112}$ & & $Y_{11 n}$ & $Y_{11}$. \\
\hline & 2 & $Y_{121}$ & $Y_{122}$ & & $Y_{12 n}$ & $Y_{12}$. \\
\hline & $\ldots$ & & & & & \\
\hline & b & $Y_{1 b 1}$ & $Y_{1 b 2}$ & & $Y_{1 b n}$ & $Y_{1 b}$. \\
\hline \multirow[t]{4}{*}{2} & 1 & $Y_{211}$ & $Y_{212}$ & & $Y_{21 n}$ & $Y_{21}$. \\
\hline & 2 & $Y_{221}$ & $Y_{222}$ & & $Y_{22 n}$ & $Y_{22}$. \\
\hline & $\ldots$ & & & & & \\
\hline & $\mathrm{b}$ & $Y_{2 b 1}$ & $Y_{2 b 2}$ & & $Y_{2 b n}$ & $Y_{2 b}$. \\
\hline$\ldots$ & $\ldots$ & $\ldots$ & $\ldots$ & & $\ldots$ & $\ldots$ \\
\hline$\ldots$ & $\ldots$ & $\ldots$ & $\ldots$ & & $\ldots$ & $\ldots$ \\
\hline$\ldots$ & $\ldots$ & $\ldots$ & $\ldots$ & & $\ldots$ & $\ldots$ \\
\hline \multirow[t]{5}{*}{$\mathrm{a}$} & 1 & $Y_{a 11}$ & $Y_{a 12}$ & & $Y_{a 1 n}$ & $Y_{a 1}$. \\
\hline & 2 & $Y_{a 21}$ & $Y_{a 22}$ & & $Y_{a 2 n}$ & $Y_{a 2}$ \\
\hline & $\ldots$ & $\ldots$ & $\ldots$ & & $\ldots$ & $\ldots$ \\
\hline & $\mathrm{b}$ & $Y_{a b 1}$ & $Y_{a b 2}$ & & $Y_{a b n}$ & $Y_{a b}$. \\
\hline & & & & & & $Y \ldots$ \\
\hline
\end{tabular}
$Y \ldots=\sum_{i=1}^{a} \sum_{j=1}^{b} \sum_{k=1}^{n} Y_{i j k}$
$\overline{Y \ldots}=\frac{Y \ldots}{a b n}$
$Y_{i} . .=\sum_{j=1}^{b} \sum_{k=1}^{n} Y_{i j k}$
$\overline{Y_{i} \cdot .}=\frac{Y_{i} \cdot .}{b n}$
$Y_{\cdot j \cdot}=\sum_{i=1}^{a} \sum_{k=1}^{n} Y_{i j k}$
$\overline{Y_{\cdot j \cdot}}=\frac{Y_{\cdot{ }^{*}}}{a n}$
$Y_{\cdot \cdot k}=\sum_{i=1}^{a} \sum_{j=1}^{b} Y_{i j k}$
$\overline{Y \cdot{ }_{* k}}=\frac{Y \cdot{ }_{\cdot k}}{a b}$
$Y_{i j}=\sum_{k=1}^{n} Y_{i j k}$
$\overline{Y_{i j}}=\frac{Y_{i j} .}{n}$
$Y_{i \cdot k}=\sum_{j=1}^{b} Y_{i j k}$
$\overline{Y_{i \cdot k}}=\frac{Y_{i \cdot k}}{b}$
$Y_{\cdot_{j k}}=\sum_{i=1}^{a} Y_{i j k}$
$\overline{Y_{\cdot j k}}=\frac{Y_{\cdot j k}}{a}$ 
Pada Rancangan Strip Plot ada 3 jenis galat yaitu galat oleh faktor pertama (galat a) galat oleh faktor kedua (galat b) dan galat oleh interaksi faktor pertama dan kedua (galat c) ${ }^{[4]}$. Pada Rancangan Strip Plot berlaku:

$J K T=J K K+J K A+J K G(a)+J K B+J K G(b)+J K A B+J K G(c)$

Dengan $J K T=$ Jumlah Kuadrat Total

$J K K=$ Jumlah Kuadrat Kelompok

$J K A=$ Jumlah Kuadrat faktor A

$J K G(a)=$ Jumlah Kuadrat Galat a

$J K B=$ Jumlah Kuadrat faktor B

$J K G(b)=$ Jumlah Kuadrat Galat b

$J K A B=$ Jumlah Kuadrat interaksi faktor A dan $\mathrm{B}$

$J K G(c)=$ Jumlah Kuadrat Galat c

Rumus-rumus untuk menghitung Jumlah Kuadrat dan Kuadrat Tengah

$$
\begin{aligned}
& F K=\frac{Y \ldots{ }^{2}}{a b n} \\
& J K T=\sum_{i, j, k=1}^{a, b, n} Y_{i j k}^{2}-F K \\
& J K K=\frac{\sum_{k=1}^{n} Y \cdot \cdot_{k}^{2}}{a b}-F K ; \quad K T K=\frac{J K K}{n-1} \\
& J K A=\frac{\sum_{i=1}^{a} Y_{i} .{ }^{2}}{b n}-F K ; \quad K T A=\frac{J K A}{a-1} \\
& J K G(a)=\frac{\sum_{i=1, k=1}^{a, n} Y_{i \cdot k}{ }^{2}}{b}-F K-J K K-J K A ; \quad K T G(a)=\frac{J K G(a)}{(a-1)(n-1)} \\
& J K B=\frac{\sum_{j i=1}^{b} Y \cdot_{j \cdot}^{2}}{a n}-F K ; \quad K T B=\frac{J K B}{(b-1)} \\
& J K G(b)=\frac{\sum_{j=1, k=1}^{b, n}{ }^{2}{ }^{2}}{a}-F K-J K B-J K K ; \quad K T G(b)=\frac{J K G(b)}{(b-1)(n-1)} \\
& J K A B=\frac{\sum_{i=1, j=1}^{a, b} Y_{i j}{ }^{2}}{n}-F K-J K A-J K B ; \quad K T A B=\frac{J K A B}{(a-1)(b-1)} \\
& J K G(c)=J K T-J K K-J K A-J K G(a)-J K B-J K G(b)-J K A B \\
& K T G(c)=\frac{J K G(c)}{(a-1)(b-1)(n-1)}
\end{aligned}
$$


Diperoleh tabel ANOVA sebagai berikut:

Tabel 2: Anova untuk Rancangan Strip Plot model Tetap

\begin{tabular}{|l|l|l|l|l|l|}
\hline $\begin{array}{c}\text { Sumber } \\
\text { Keragaman }\end{array}$ & \multicolumn{1}{|c|}{$\begin{array}{c}\text { Derajat } \\
\text { Bebas }\end{array}$} & $\begin{array}{c}\text { Jumlah } \\
\text { Kuadrat }\end{array}$ & $\begin{array}{c}\text { Kuadrat } \\
\text { Tengah }\end{array}$ & F hitung & F tabel \\
\hline Kelompok & $(\mathrm{n}-1)$ & JKK & KTK & & \\
\hline A & $(\mathrm{a}-1)$ & JKA & KTA & $\frac{K T A}{K T G(a)}$ & $F_{(a-1) ;(a-1)(n-1)}(\alpha)$ \\
\hline Galat (a) & $(\mathrm{a}-1)(\mathrm{n}-1)$ & JKG(a) & KTG(a) & & \\
\hline B & $(\mathrm{b}-1)$ & JKB & KTB & $\frac{K T B}{K T G(b)}$ & $F_{(b-1) ;(b-1)(n-1)}(\alpha)$ \\
\hline Galat (b) & $(\mathrm{b}-1)(\mathrm{n}-1)$ & JKG(b) & KTG(b) & & \\
\hline AB & $(\mathrm{a}-1)(\mathrm{b}-1)$ & JKAB & KTAB & $\frac{K T A B}{K T G(c)}$ & $F_{(a-1) ;(b-1) ;(a-1)(b-1)(n-1)}(\alpha)$ \\
\hline Galat (c) & $(\mathrm{a}-1)(\mathrm{b}-1)(\mathrm{n}-1)$ & JKG(c) & KTG(c) & & \\
\hline Total & abn-1 & JKT & & & \\
\hline
\end{tabular}

Kriteria ujinya adalah Ho ditolak jika $\mathrm{F}$ hitung $>\mathrm{F}$ tabel yang bersesuaian. Jika Ho ditolak maka dilakukan uji lanjutnya salah satunya dengan metode Duncan, dengan lebih dahulu menghitung standart bakunya

Nilai ktitis Duncannya $R_{p}=r_{\alpha ; p ; d b g a l a t} S_{\bar{d}} / \sqrt{2}$

$r_{\varepsilon ; p ; d b g a l a t}$ dicari dari tabel Duncan dengan $\mathrm{p}=2,3, \ldots$, i dengan $\mathrm{i}$ adalah banyaknya taraf dari faktor yang dibandingkan

Tabel 3: Standart baku untuk Rancangan Strip Plot model Tetap

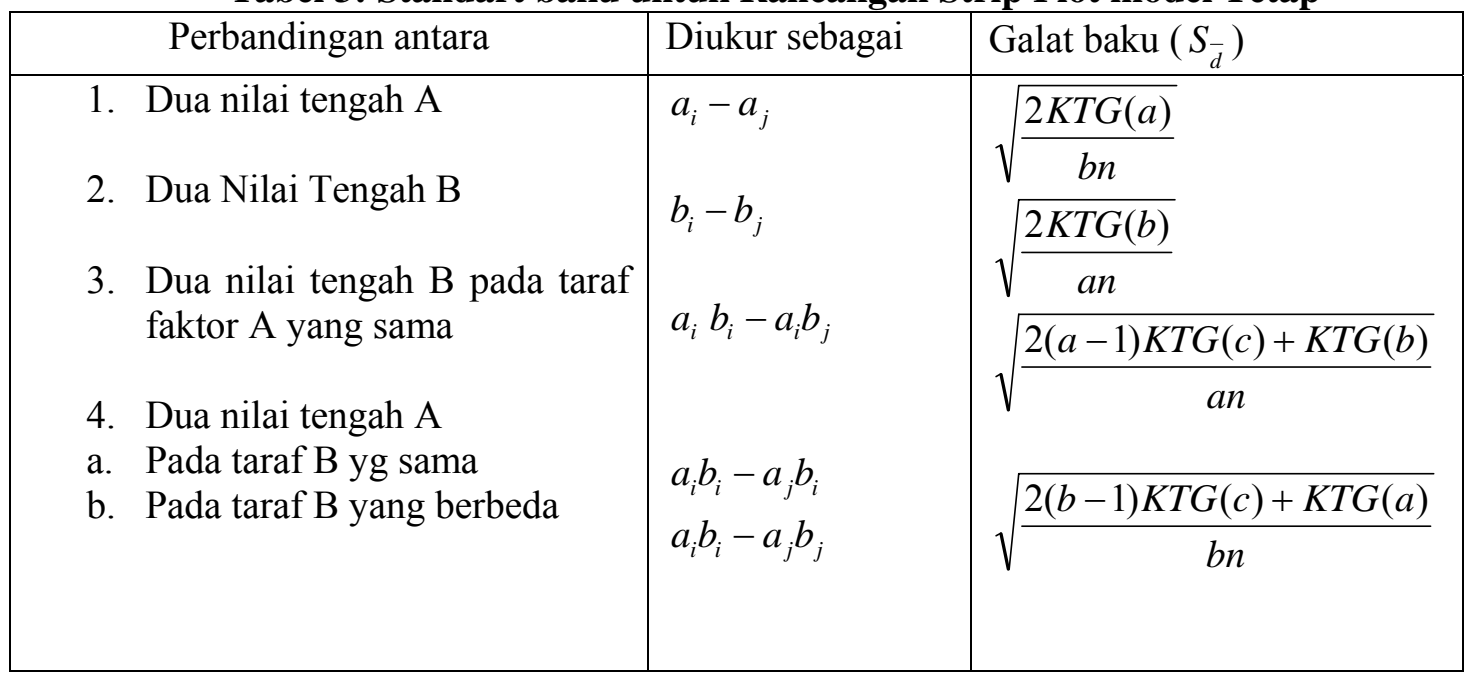

\section{Pembahasan}

Untuk memperjelas pembahasan tentang Rancangan Strip Plot, dibawah ini akan diambilkan contoh terapannya dari data lapangan. Ingin dipelajari pengaruh faktor penyinaran dan jenis pupuk terhadap produksi bobot kering sejenis rumput untuk pakan ternak. Dari dua macam penyinaran (Eo, E1) dan tiga jenis pupuk (P0, P1, P2) diamati produksi bobot keringnya. Dianggap percobaan lebih mementingkan faktor interaksi dibanding faktor utamanya, dan hasil pengaamatannya sebagai berikut: 


\begin{tabular}{|l|c|r|r|r|}
\hline \multirow{2}{*}{$\begin{array}{l}\text { Jenis } \\
\text { Pupuk }\end{array}$} & Penyinaran & \multicolumn{3}{|c|}{ Kelompok } \\
\cline { 2 - 5 } & & 1 & 2 & 3 \\
\hline P0 & E0 & 788.38 & 788.95 & 772.67 \\
\cline { 2 - 5 } & E1 & 811.23 & 829.90 & 817.88 \\
\hline \multirow{2}{*}{ P1 } & E0 & 1496.60 & 1342.56 & 1357.90 \\
\cline { 2 - 5 } & E1 & 1538.49 & 1639.10 & 1485.75 \\
\hline P2 & E0 & 1279.92 & 1422.18 & 1479.64 \\
\cline { 2 - 5 } & E1 & 1380.82 & 1452.72 & 1526.25 \\
\hline
\end{tabular}

Sumber data: Teguh Wibowo, Mahasiswa Magister Ilmu Ternak Undip

Dengan menggunakan program Minitab 14.10, asumsi normalitas baik galat a, galat $b$, dan galat $c$ dipenuhi dengan nilai Kolmogorov Smirnov masing-masing 0.185; $0.212 ; 0.105$ dan $\mathrm{P}$ value masing-masing $0.039 ; 0.01 ; 0.15$. Sedangkan homogenitas varian galat a, galat $b$, galat $\mathrm{c}$ juga dipenuhi melalui uji Barlett dengan nilai statistik uji masing-masing $4.85 ; 1.0 ; 8.26$ dan $\mathrm{p}$ value masing-masing $0.183 ; 1.0 ; 0.310$

Dengan menggunakan paket program SAS 6.12 diperoleh: General Linear Models Procedure Dependent Variable: RESPON

$\begin{array}{lr}\text { Source } & \text { DF } \\ \text { Model } & 17 \\ \text { Galat c } & 6 \\ \text { Corrected Total r-Square } & 23 \\ & \text { R-992446 }\end{array}$

Sum of
Squares
2015227.195
15337.902
2030565.097
C.V.
3.976162

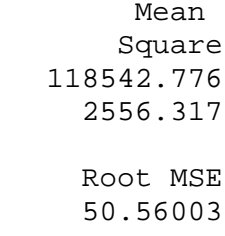
$\begin{array}{ll}\text { F Value } & \mathrm{Pr}>\mathrm{F} \\ 46.37 & 0.0001\end{array}$

Source

KEL

Type III SS

45025.514

1793502.645

103959.482

Galat a

53690.230

4942.738

Galat b 14106.586
Mean Square
22512.757
597834.215
17326.580
53690.230
2471.369
4702.195

$P^{\star} E$

Tests of Hypotheses using the Type III MS

$\begin{array}{lrr}\text { Source } & \text { DF } & \text { Type III SS } \\ \mathrm{P} & 3 & 1793502.645\end{array}$

Tests of Hypotheses using the Type III MS for

Source

DF

Type III SS

for Galat a

Mean Square 597834.215

E

$1 \quad 53690.23010$

for Galat b a
Mean Square

53690.23010

$\begin{array}{cr} & \text { RESPON Mean } \\ & 1271.579 \\ \mathrm{~F} \text { Value } & \mathrm{Pr}>\mathrm{F} \\ 8.81 & 0.0164 \\ 233.87 & 0.0001 \\ 6.78 & 0.0174 \\ 21.00 & 0.0038 \\ 0.97 & 0.4326 \\ 1.84 & 0.2406 \\ \text { an error } & \text { term } \\ \mathrm{F} \text { Value } & \mathrm{Pr}>\mathrm{F} \\ 34.50 & 0.0004 \\ \text { an error } & \text { term } \\ \mathrm{F} \text { Value } & \mathrm{Pr}>\mathrm{F} \\ 21.72 & 0.0431\end{array}$

Berdasarkan output diatas diketahui bahwa $99.2446 \%$ keragaman dari produksi bobot kering sejenis rumput untuk pakan ternak mampu dijelaskan oleh faktor penyinaran dan jenis pupuk dengan koefisien keragaman sebesar 3.976162.

Jika diambil $\alpha=5 \%$ dapat disimpulkan bahwa :

1. Ada pengaruh penyinaran terhadap produksi bobot kering sejenis rumput, dengan $F$ hitung 34.50 dan $\mathrm{P}$ value 0.0004

2. Ada pengaruh jenis pupuk terhadap produksi bobot kering sejenis rumput, dengan $F$ hitung 21.72 dan $P$ value 0.0431

3. Tidak ada pengaruh interaksi antara penyinaran dan jenis pupuk terhadap produksi bobot kering dengan F hitung 1.84 dan $\mathrm{P}$ value 0.2406 


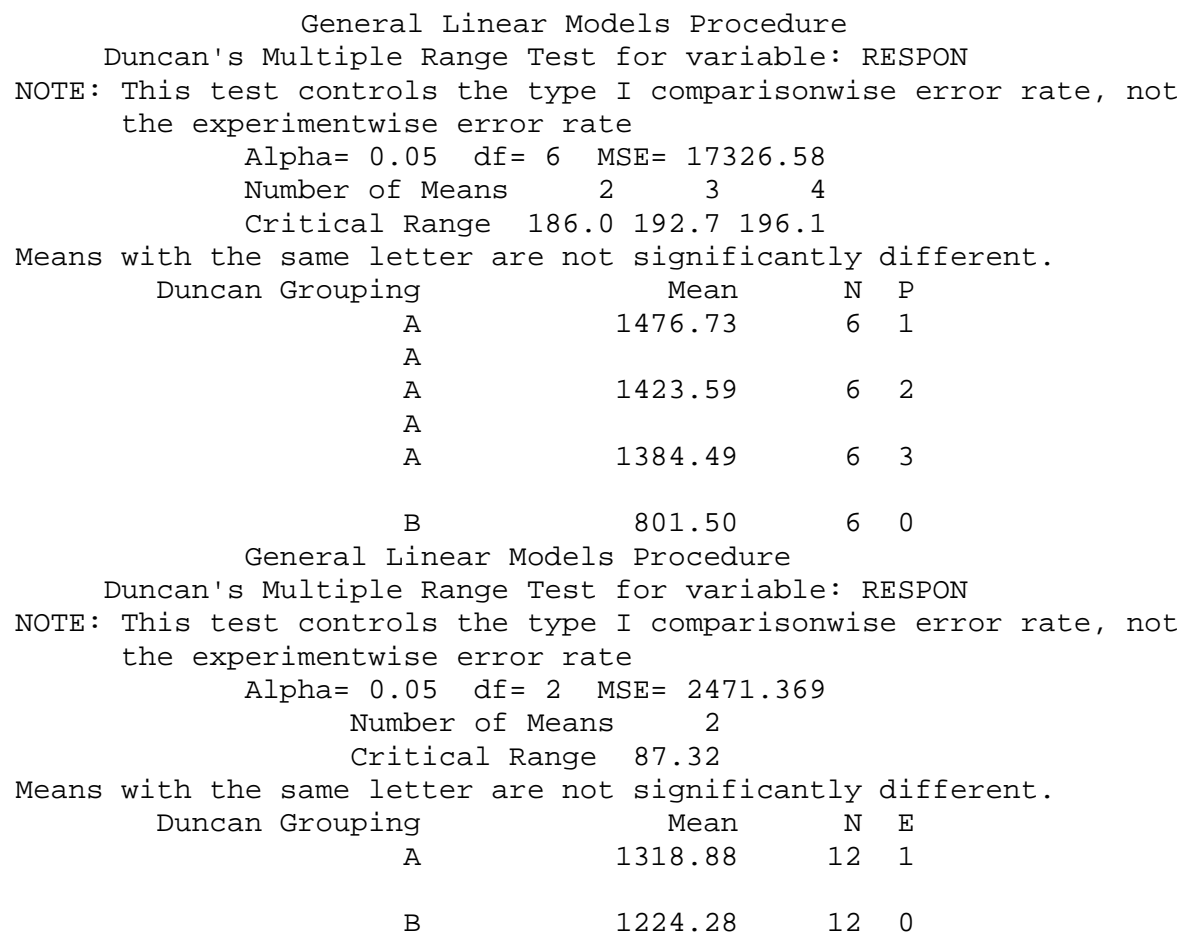

Berdasarkan uji wilayah Duncan, dengan jenis pupuk P0 akan memberikan ratarata produksi bobot kering sejenis rumput paling rendah dan berbeda dengan yang lain. Sedangkan untuk jenis pupuk P1, rata-rata produksi bobot kering sejenis rumput tertinggi dan tidak berbeda dengan P2 dan P3. Untuk faktor penyinaran E1 akan memberikan rata-rata produksi bobot kering sejenis rumput lebih tinggi dibandingkan E2.

\section{Kesimpulan}

Dari uraian di atas dapat disimpulkan bahwa Rancangan Strip Plot digunakan untuk percobaan dua faktor dimana kedua faktor diletakkan sebagai petak utama karena yang dipentingkan interaksi kedua faktornya.

Jika dinginkan faktor pertama berpengaruh secara nyata terhadap respon, maka dilakukan uji lanjut dengan galat yang digunakan adalah galat a. Jika faktor kedua berpengaruh secara nyata terhadap respon, maka dilakukan uji lanjut dengan galat yang digunakan adalah galat $b$. Jika interaksi antara faktor pertama dan kedua berpengaruh secara nyata terhadap respon, maka dilakukan uji lanjut dengan galat yang digunakan adalah galat $\mathrm{c}$.

Dari contoh kasus, kedua faktor berpengaruh terhadap respon demikian juga interaksinya dengan melalui uji wilayah Duncan. Asumsi Normalitas dan Homogenitas Variansi untuk masing-masing galat terpenuhi.

\section{DAFTAR PUSTAKA}

1. Ansori, A. dan Sumertajaya, M., Perancangan Percobaan dengan aplikasi SAS dan Minitab, IPB PRESS. Bogor, 2000.

2. Gaspersz, V., Metode Perancangan Percobaan . C.V Armico, Jakarta, 1991.

3. Gomez, K.A. and Gomez A.A. Procedures for Agricultural Research. John Wiley \& Sons, Inc., 1984. 
Media Statistika, Vol. 1, No. 1, Juni 2008: 35-42

4. Montgomery, D.C. Design and Analysis of Experiments. Fifth Edition. John Wiley \& Sons, Inc., New York, 2005.

5. Steel,R.G.D., Torrie, J.H. and Dickey, D.A., Principles and Procedures of Statistics a Biometrical Approach, Third Edition. McGraw-Hill, Inc., Singapore, 1997.

6. Sugandi, E. dan Sugiarto, Rancangan Percobaan. Andi Offset, Yogyakarta, 1994. 